\title{
Regulative effect for natural killer cell by hot spring hydrotherapy-Quantitative and qualitative discussion
}

\author{
Nobuo Yamaguchi ${ }^{*}$, Wenhan Wan $^{1}$, Daisuke Sakamoto ${ }^{2}$, Amat Nurmuhammad $^{3}$, Kengo \\ Matsumoto $^{1}$, Takafumi Takei ${ }^{1}$, Katsuko Okuzumi ${ }^{4}$, Tsugiya Murayama ${ }^{5}$, Takashi Takahashi ${ }^{4}$ \\ ${ }^{1}$ Ishikawa Medicinal Products Research Center, Kanazawa, Japan; ${ }^{*}$ Corresponding Author: serumaya@kanazawa-med.ac.jp \\ ${ }^{2}$ Department of Heart Surgery, Kanazawa Medical University, Himi Municipal Hospital, Himi City, Japan \\ ${ }^{3}$ Uighur Medicine Department of Xinjiang Medical University, Urumqi City, China \\ ${ }^{4}$ Laboratory of Infectious Diseases, Graduate School of Infection Control Sciences, Kitasato University, Tokyo, Japan \\ ${ }^{5}$ Deaprtment of Microbiology and Immunology, Faculty of Pharmaceutical Sciences, Hokuriku University, Japan
}

Received 9 September 2013; revised 9 October 2013; accepted 16 October 2013

Copyright (C) 2013 Nobuo Yamaguchi et al. This is an open access article distributed under the Creative Commons Attribution License, which permits unrestricted use, distribution, and reproduction in any medium, provided the original work is properly cited. In accordance of the Creative Commons Attribution License all Copyrights (C) 2013 are reserved for SCIRP and the owner of the intellectual property Nobuo Yamaguchi et al. All Copyright (C) 2013 are guarded by law and by SCIRP as a guardian.

\section{ABSTRACT}

Along with maintaining immune competent cells, one of the purposes of cancer patient is regulating the first line of defense for survival. Moreover, the factors that influence the acquired immune activity are systemic metabolic disorder in diabetes, malnutrition, extreme exhaustion, stresses, aging and medical side effect such as chemotherapy. So we have to select appropriate menu to regulate immune function through leukocyte storage. Especially, NK cell is first line of defense against virus infected cell and/or tumor cell. In order to recommend the effect of hot spring hydrotherapy on the peripheral white blood cells as a parameter for complementary and alternative medicine (CAM) within a short period, the granulocytes, lymphocytes, lymphocyte subsets in their peripheral blood were monitored. In the young group (35 or less), the number of granulocytes clearly decreased after hydrotherapy. In the older group (over 35 years old), the total number of leukocytes and lymphocytes significantly increased after the therapy. Using a FACScan, we investigated CD2, CD4, CD8, CD16, CD19 and CD56 positive cell as well as the cytokine containing cell, as direct assessment for immunological preparation (IFN- $\gamma$, IL-4 and IL-1 $\beta$ ). After hydrotherapy, the CD16 ${ }^{+}$cells also increased outstandingly. However, the $\mathrm{CD}_{19^{+}}$cells clearly decreased. Moreover, there was a decrease in the cytokine-pro- ducing cell count of subjects whose blood cells had a higher number of the cell level before. All of the results indicated that hot spring hydrotherapy could regulate the immune system even in normal human. Like this, blood hormonal level was measured in order to know the mechanism of the quantitative and qualitative, adjustment of the leucocytes becomes possible within a short term. As a result of measuring, 7 kinds of hormone including mainly adrenocortical hormones, adrenalin level reduced in constitution dependent manner. From these results, it was suggested that the quantitative and qualitative fluctuation of the leukocyte by the hydrotherapy is closely related to dynamics of blood hormonal level.

Keywords: Hot Spring Hydrotherapy; Leukocyte Regulation; NK Cell; Quantitative Regulation of Lymphocyte; Qualitative Regulation of Lymphocyte

\section{INTRODUCTION}

Despite our defense system, the overwhelming problems of possessing our dual system, the innate and adoptive do not seem to guard or even prevent the development of one internal threat to survival. Moreover, every individual exposes to the risk of immunodeficiency in daily life with both internal and externals. Especially, NK cell is first line of defense against virus infected cell and/or tumor cell. So a cancer patient requires to select appropriate menu to regulate immune function as in 
quantitative as well as qualitative even for low pathogenic microorganisms.

The factors that influence the acquired immune activity are systemic metabolic disorder such as diabetes, malnutrition, extreme exhaustion, stress, aging and medical side effect in cancer [1-10]. So we have to select appropriate menu to regulate immune function through leukocyte storage. The menu had been summarized and listed as CAM: complementary and alternative medicine [11-18].

Many systems are in place to evaluate Western therapies that aim at healing the symptoms of an illness. However, when the purpose of a therapy is to enhance the QOL of healthy people, such as some alternative medical therapies, no widely-accepted evaluation system has been established. To fill this lack, we would like to propose the number and functions of leukocyte subsets as indicators for the evaluation of alternative therapies.

In this report, we would like to focus on the effect of hot spring hydrotherapy, especially in regulatory effect of natural killer cell in number and function.

\section{MATERIALS AND METHODS}

\subsection{Subjects and Methods}

Twelve to 25 individuals per group were tested from the spring in 2005 to autumn. For hormonal analysis, all the volunteers were informed and consented by the ethics committee of Kanazawa Medical University. According to the percentage of lymphocytes or granulocytes in the total leukocytes, the hydrotherapy group was further divided into two types: subjects whose granulocyte number was over $60 \%$ belonged to the $\mathrm{G}$ type, those whose lymphocyte number was over $40 \%$ belonged to the $\mathrm{L}$ type (Table 1).

The hot springs selected for these tests were Wakura Onsen Spa (a conc. sodium chloride with chlorinated soils, Nanao City, Ishikawa Pref.), Chugu Onsen Spa (a dil. sodium chloride with sodium carbohydrate, Hakusan City, Ishikawa Pref.) with a Japanese style of bathing that free from under wear. The water temperature was 41 degrees centigrade, fluctuating up or down by 1 degree centigrade.

On the first day of the trial, five-milliliters of blood were drawn from the forearm vein of all the subjects at 4 o'clock p. m. During that evening and the next morning, the hydrotherapy group bathed in the hot spring two to three times, for 20 minutes each time. Finally, at 4 o'clock p. m. on the second day, the blood of all the subjects was sampled again, avoiding a circadian rhythm of leukocyte subset, granulocyte and lymphocyte [19-21]. Heparin was used as an anti-coagulating reagent (Figure 1).

\subsection{Leukocyte Count}

We accessed each variation of leukocyte with the data avoid circadian rhythm of leukocytes. The total number of leukocytes was recorded with a standard counter. In the differential counting, 200 cells were counted in each
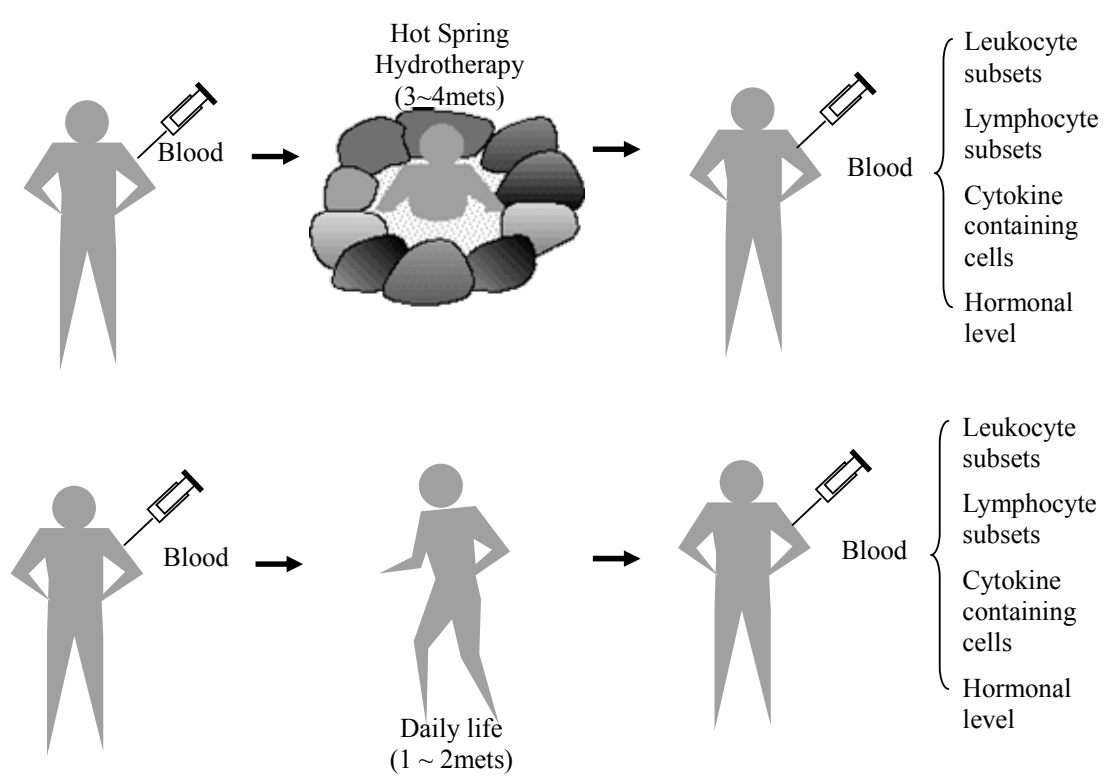

Figure 1. Experimental protocol. The age of the volunteers ranged from 18 to $87 \mathrm{n}=$ 25 ). They were separated into two groups, 35 years old and younger, and 36 and older, according to the results in this text. One group took a bath two to three times for 20 min, within a $24 \mathrm{hr}$ period. Blood was collected from a peripheral venula before hydrotherapy and 24-hrs later. The blood was prepared as plasma and examined by a FACScan. Details of the procedures are within the text [23]. 
May-Grunwald-Giemsa stained smear. The numbers of granulocytes, coenocytes and lymphocytes were determined, respectively.

\subsection{Lymphocytes and Lymphocyte Subset Analysis}

The whole blood obtained from the subjects was washed twice with PBS (phosphate buffered saline, $\mathrm{pH}$ 7.2). The suspensions were treated with fluorescent monoclonal antibodies (FITC-conjugated anti-human CD2, CD4, CD8, CD16, CD19 and CD56) separately. After 30 minutes of staining at 4 degrees centigrade, the cells were analyzed by a FACScan (Becton Dickinson Co. Ltd. U.S.A.).

\subsection{Cytokine Containing Cell Analysis}

The blood cell suspensions were cultured with PMA (phorbol 12-myristate 13-acetate), Ionomycin and BSA (bovine serum albumin) for $4-5$ hours at 37 degrees centigrade. After that, the cell suspensions were stained using the monoclonal antibodies of PE-IL-4, FITC-IFN- $\gamma$ and FITC-IL-1 $\beta$, respectively. Then they were analyzed by the FACScan (Becton Dickinson Co. Ltd. U.S.A.). The antibodies and reagents used in the entire test were purchased from Becton Dickinson Immunocytometry system (U.S.A.).

\subsection{Hormonal Level Analysis}

The serum obtained from the subjects was used for hormonal analysis. The concentration of adrenocorticotropic hormone (ACTH), triiodothyronine (T3), thyroxine [13] and thyroid stimulating hormone (TSH) were measured by radioimmunoassay (RIA). Adrenalin, noradrenalin and dopamine were measured by high performance liquid chromatography (HPLC). The examination of these hormonal level was ordered in Ishikawa Health Service Association (Institution by Public Organization,
Ishikawa, Japan).

\subsection{Statistical Analysis}

The statistical comparisons between two groups (before and after hot spring hydrotherapy) for the test of significant difference were performed using paired t-test and wilcoxon signed-ranks test. Further, the test of the correlation were performed a spearman's correlation coefficient by rank test. Data are expressed as means \pm standard error of mean (SE). A P value $<0.05$ was considered to be statistically significant.

\section{RESULTS}

\subsection{The Effect of Hot Spring Hydrotherapy on the Leukocyte Count Correlated with the Age and Original Basic Count of the Individuals}

We accessed each variation of leukocyte with the data avoid circadian rhythm of leukocytes [19-21]. Table 1 shows the total numbers of leukocytes, granulocytes and lymphocytes from peripheral blood collected before and after hot spring hydrotherapy in the old ager and young ager [22]. The quantitative variation of the two groups differed. In the young ager, the total number of WBC (p $<0.05)$ and granulocytes $(p<0.01)$ clearly decreased. On the other hand, the total number of WBC and lymphocytes significantly increased $(\mathrm{P}<0.01)$ after hydrotherapy in the old ager [22]. Furthermore, the results show that changes in the leukocyte count and subset count had a negative relationship before and after hydrotherapy. In other words, subjects who had a higher cell count level before hydrotherapy tended to show a decrease in the number of WBC $24 \mathrm{hrs}$ after hydrotherapy. There was a significant correlation between age and rate of change $(p<0.01)$. Since the turning point got at 35 years old, we separated the participants into a young ager (under 35) and an old ager (over 36) group (Figure 2).

Table 1. The regulation by HSH in number of WBC according to age. The volunteers were divided into two groups, 35 years old and younger, and 36 and older, corresponding to the up-regulation or down-regulation of peripheral WBC in the text [23]. The WBC subsets were then counted morphologically according to granulocyte and lymphocyte number.

\begin{tabular}{ccccc}
\hline & & \multicolumn{2}{c}{ The number of cells $\left(\mathrm{X} \pm \mathrm{SD} / \mathrm{mm}^{2}\right)$} & \\
\hline \multirow{2}{*}{ Group } & type of cells & before bathing & after bathing & P value \\
\hline \multirow{2}{*}{ Old ager } & WBC & $5940.00 \pm 1035.85$ & $7400.00 \pm 1017.34$ & $<0.01$ \\
& granulocyte & $3247.60 \pm 841.78$ & $3769.24 \pm 844.98$ & $<0.05$ \\
& lymphocyte & $2127.61 \pm 577.92$ & $2935.22 \pm 655.83$ & $<0.01$ \\
\hline \multirow{2}{*}{ Young ager } & WBC & $6631.24 \pm 1413.30$ & $6098.21 \pm 1326.50$ & $<0.05$ \\
& granulocyte & $4100.86 \pm 1003.51$ & $3251.44 \pm 885.13$ & $<0.01$ \\
& lymphocyte & $1788.00 \pm 598.52$ & $1670.86 \pm 431.76$ & $>0.05$ \\
\hline
\end{tabular}




\subsection{The Effect of Hot Spring Hydrotherapy on the Number of Lymphocyte Subsets Also Correlated with the Original Basic Number of the Individuals}

The results varied among the lymphocyte subsets before and after hot spring hydrotherapy. After hydrotherapy, the $\mathrm{CD} 16^{+}, \mathrm{CD} 8^{+}$and $\mathrm{CD} 19^{+}$cells increased in the young ager. Meanwhile, the $\mathrm{CD} 16^{+}$cells increased in the old ager while the $\mathrm{CD} 19^{+}$cells decreased remarkably ( $\mathrm{P}$ $<0.01)$. This quantitative change in lymphocytes are shown in Figure 3 Except for $\mathrm{CD} 8^{+}$cells, the $\mathrm{CD} 2^{+}$, $\mathrm{CD}^{+}, \mathrm{CD} 16^{+}, \mathrm{CD} 19^{+}$and $\mathrm{CD} 56^{+}$cells, all showed regulative variations. There was a strong correlation between the variable ratio and the value before hydrotherapy, high values tended to decrease and low values tended to increase in CD2, CD4 and CD16 ( $\mathrm{r}=0.692, \mathrm{r}=0.558, \mathrm{r}=$ $0.488, \mathrm{p}<0.001)$, next are CD19, CD56 $(\mathrm{r}=-0.260, \mathrm{r}=$ -0.225 ). Only CD8 cell did not alter the number in the day before $(\mathrm{r}=-0.150)$.

\subsection{Hot Spring Hydrotherapy Affected the Functional Changes in Cytokine-Containing Cells}

To test whether hot spring hydrotherapy affected the functional maturation of immunocytes within a short time, we further investigated the number of cytokine containing cells by FACS analysis. This method reveals cytokine producing cell number by peering off the surface of lymphocyte, enable to express cells in festival evening, compare than serum cytokine level that correspond to paper tips of post festival.

Figure 4 shows the effect of hot spring hydrotherapy on cytokine production. Even though the increase in IFN $-\gamma$ containing cells had statistical significant $(r=$ $-0.323, \mathrm{P}<0.01)$, the increase in IL-4 was remarkable ( $\mathrm{r}$

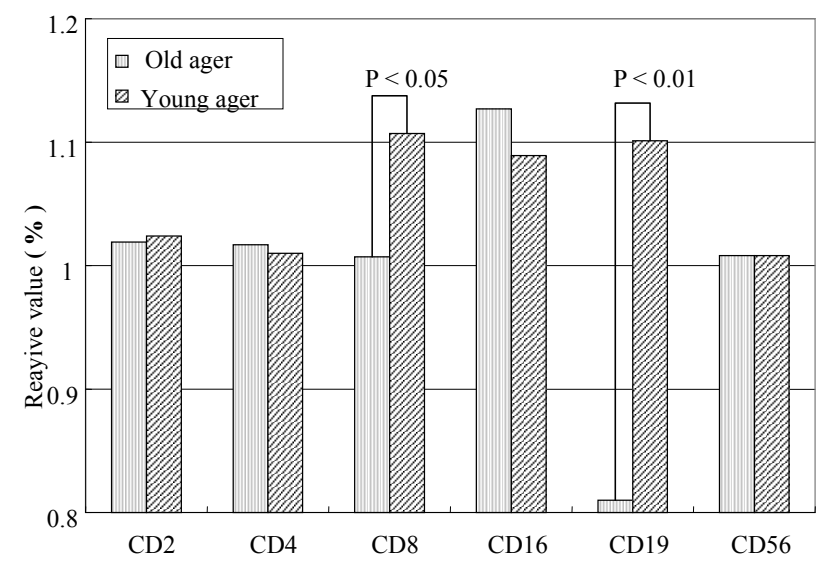

Figure 2. The variation of lymphocyte subsets after hot spring bathing. The vertical axis present the ratio of lymphocyte subsets percentage after hot spring bathing vs before hot spring hydrotherapy.

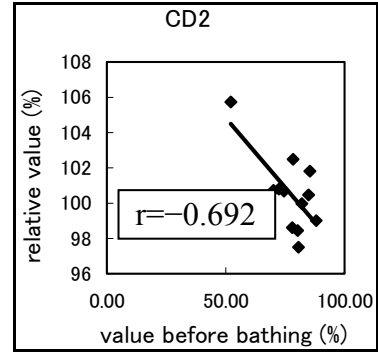

(a)

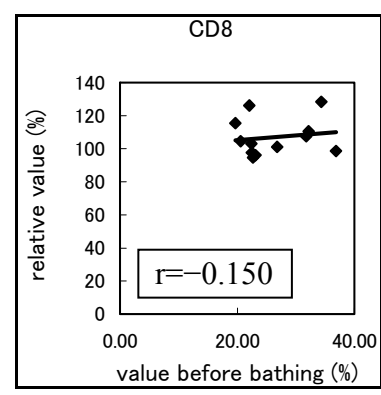

(c)

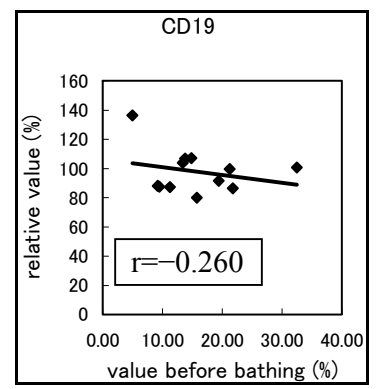

(e)

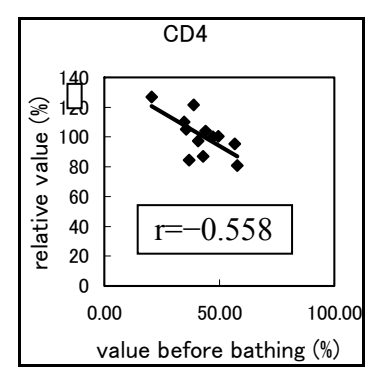

(b)

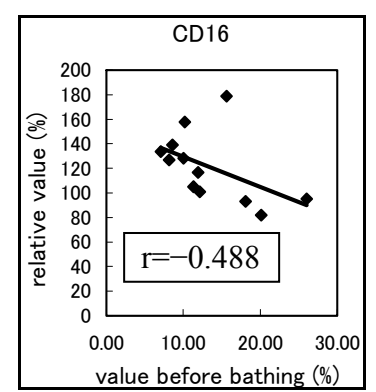

(d)

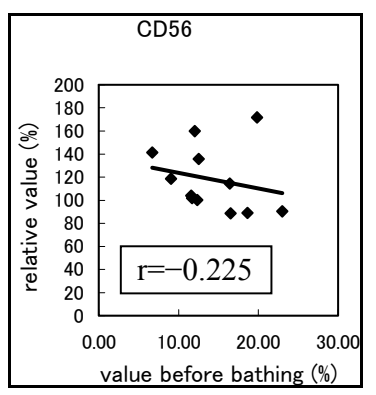

(f)
Figure 3. The regulation in the lymphocyte subsets before and after bathing. The variation rate is shown for $\mathrm{CD}$ positive Cells, CD2, CD4, CD8, CD16, CD19 and CD56.

$=-0.560)$ while the IL- $1 \beta$ containing cell counts showed a less significant( $\mathrm{r}=-0.237)$. In addition, before and after hydrotherapy, the levels of IFN- $\gamma$ and IL4 or IL- $1 \beta$ also had regulated in a constitution dependent manner. After hydrotherapy, there was a decrease of cytokineproducing cells in the subjects who previously had a higher level of the number. The changes depended on the age and the basic level of the white blood cells number in the blood of the individuals.

\subsection{Hot Spring Hydrotherapy Modulates Hormonal Level in Blood}

The peripheral blood was sampled twice from the volunteers at before and after 24 hours of the hydrotherapy. In order to confirm regulatory effect by HSH within a short time, we tried to access the effect on the hormonal level. As a measurement item, thyroid hormone and 4 kinds of hormone related to emotion were selected. As a result of measuring, the blood hormonal level around the 


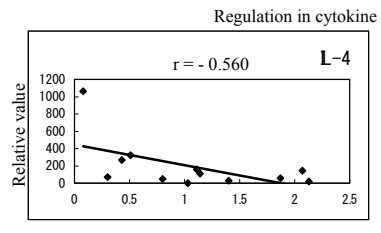

Cell num ber before bathing $(\times 100)$

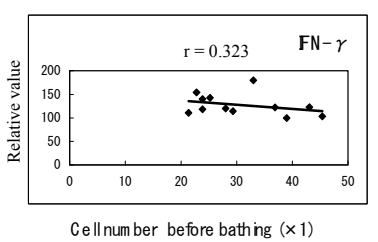

Figure 4. Cytokine producing cell. The relative numbers of cytokine containing cells in IL- $1 \beta$, IL-4 and IFN- $\gamma$ were counted and shown on the vertical line. Each value on the first day is indicated at the horizon point. The correlation efficiencies of $\mathrm{r}=-0.237, \mathrm{r}=-0.560$ and $\mathrm{r}=-0.323$ indicated that IL- 4 , IL- $1 \beta$ and IFN- $\gamma$ containing cells were significantly regulated by hot-spring hydrotherapy.

hot spring hydrotherapy, adrenalin and noradrenalin showed a regulation decrease in most individuals $(\mathrm{r}=$ $-0.62016, \mathrm{r}=-0.29835)$, while dopamine level showed an overall increase $(\mathrm{r}=-0.22819)$ but in constitution dependent. On the other hormonal level, the T3 and T4 also fluctuated by HSH. We also found a negative correlation between the variable ratio and the value before hydrotherapy in adrenalin level (Figure 5): high values tended to decrease and low values tended to increase, showing regulation $(\mathrm{r}=-0.62016)$.

\section{DISCUSSION}

In Japan, it is traditionally accepted that hot spring hydrotherapy is as beneficial to the health as moderate exercise. Many studies have shown that moderate exercise can improve physical immune function, even though the details of the mechanism remain unclear. With our study and reproducible results, we can say that the effect of hot spring hydrotherapy is also connected with the function of the immune system. The cell count and function of granulocyte, monocyte, lymphocyte and lymphocyte subsets including NK-cells in the peripheral blood had changed after hydrotherapy. Our data also showed that the variations in peripheral blood occurred according to age. The younger group showed a clear decrease in the number of granulocytes while the total number of leukocytes increased in the older group. Other interesting results included the negative relationship in cell counts of the younger and older groups and differing data between the $\mathrm{G}$ and $\mathrm{L}$ types. One possible reason for the cell count increase may be that the temperature of a hot spring is always higher than normal body temperature, causing perspiration that may result in hemo-concentration. In order to avoid this short term phenomenon, we did not measure the blood samples immediately, but 24 hours after hot spring hydrotherapy $[11,12,18]$. This gave the subjects enough time to drink and supplement the extracellular fluid that was lost during hot spring hydrotherapy. The other reason for the collection schedule is that the lymphocyte and granulocyte numbers change with the circadian rhythm $[19,20]$.

The leukocytosis in individuals may also be associated with the regulation of the nervous system and hormones. It is well known that corticosteroids are involved in the maturation and differentiation of lymphocytes and monocytes. On the other hand, taking corticosteroids can result in transient lymphocytopenia. We thought that hot spring hydrotherapy would release stress and therefore reduce the levels of corticosteroids and other similar hormones [22]. The leukocytes were then redistributed from the body compartments such as central lymphoid organs from the circulation into other body compartments in the younger participants and into the circulation of the older individuals. In this way, the cell counts in the blood could be maintained at constant and average levels or so called homeostasis [23]. Such regulation may occur not only through hot spring bathing but also by the hot water hydrotherapy such as that of the Japanese public bath system. A critical assessment of this issue will be a major focus of future research.

After hot spring hydrotherapy, the subsets of the $\mathrm{T}$ lymphocytes changed more clearly in the younger group than in the older one. The percentages of $\mathrm{CD} 4^{+}$and $\mathrm{CD} 8^{+}$ subsets were enhanced significantly, especially the percentage of $\mathrm{CD}^{+}$cells. This may have also been associated with hormones, which mobilized lymphocytes into the marginal pool [19].

We found that the function of lymphocytes significantly increased after hot spring hydrotherapy. We know that cytokine IFN- $\gamma$, which is closely associated with the activity of cellular immunity, is secreted from Th1 cells $[19,20]$. The IL-4 associated with humoral immunity is regulated by Th2 cells. Simon et al. confirmed that the level of IL-4 in the circulation was enhanced after exercise, and since IL-1 promoted immune responsiveness, it may be an important link between fever and the function that enables the host to defend itself against infection [24]. The increase of cytokine-containing cells in IL-4 demonstrated that hot spring hydrotherapy could enhance the immune system's ability to fight off infection by augmenting humoral immunity. It has been reported that all kinds of environmental stimulation activate the autonomic nervous system and then influence the immune system through adrenergic receptors on granulocytes and cholinergic receptors on lymphocytes [20]. The variations in the hormone and $\beta$-adrenergic receptors of lymphocytes may cause the rise in lymphocyte activity. This would be an important and interesting point to investigate further. 


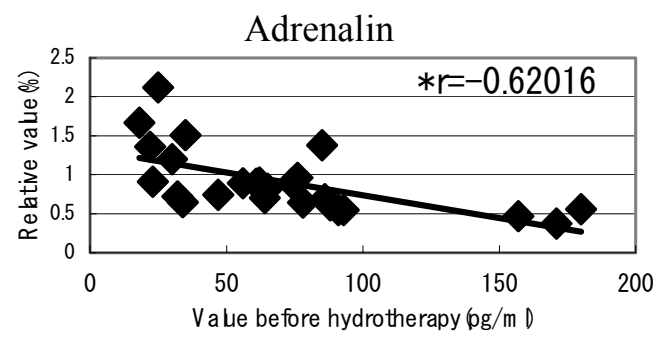

(a)

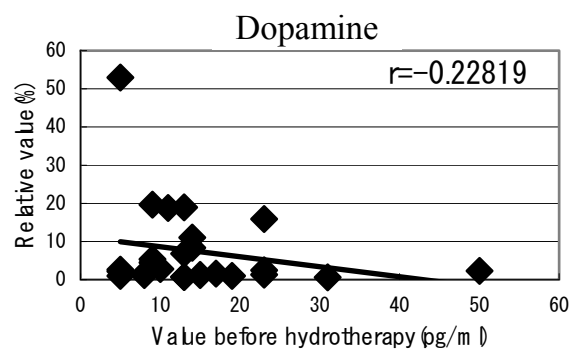

(c)

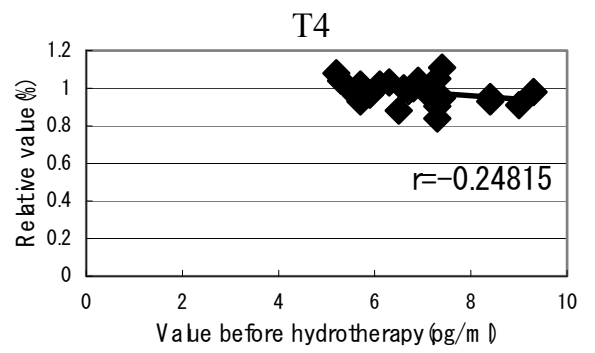

(e)

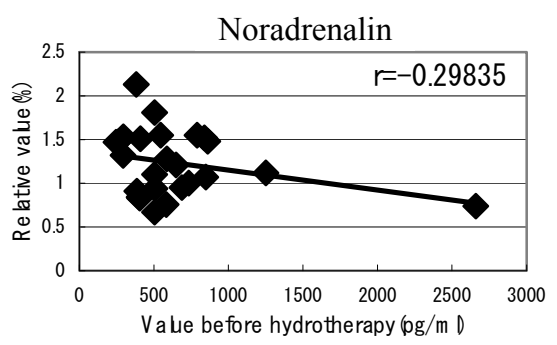

(b)

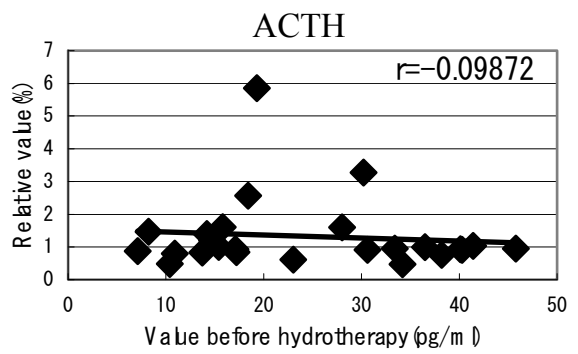

(d)

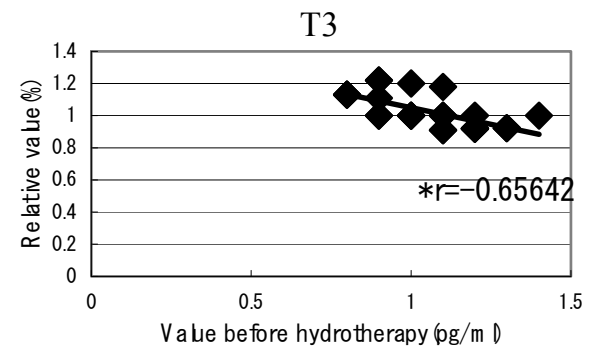

(f)

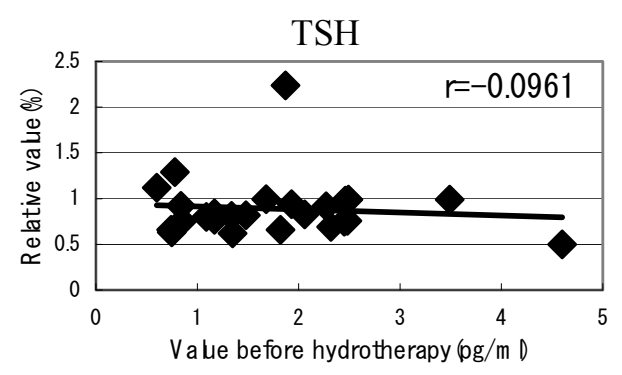

(g)

Figure 5. The relationship between the hormonal level. The relationship between the hormonal level before hydrotherapy and the relative changes of hormonal level that changed before and after hydrotherapy Data represent variable ratio and the value before hydrotherapy $\left(\mathrm{n}=25\right.$ persons). ${ }^{*} \mathrm{P}$ $<0.01$.

The $\mathrm{CD} 16^{+}$cell and $\mathrm{CD} 56^{+}$cell counts also increased in the two groups, showing that hot spring hydrotherapy can promote the production of Natural killer (NK) cells which play a vital role in protecting against viral infections and tumors [25-29]. This alteration in NK cell count following hot spring hydrotherapy is being followed with intense interest. Further IFN- $\gamma$ containing cell also regulated by $\mathrm{HSH}$, showing NK cell regulation found both quantitative and qualitative.

In this report, we could access the cytokine containing cell, as a qualitative assessment. Many of reports concern cytokine as serum level. However, serum cytokine is so to say, paper tips of some festival. The real intense of festival have to be a population of festival evening, approaching cytokine containing cell in the immunological affair.

There was much variation in the negative relationships found in this test, showing similar tendencies to those seen in the rate of breathing and heart rate with moderate exercise (3 - 4 mets). This means that hot spring hydrotherapy can enhance the activity that regulates and maintains the balance of human beings, leading to immune 
function regulation.

The immune response is a phenomenon that include well-programmed interactions among different cell types and molecules. Moriguchi [27], reported the psychological movement influences progress and prognosis in consumptive patients. Recent evidence has provided information on the bidirectional communication between the immune and neuro-endocrine systems [23,24]. Psychoneuro system recognizes the external environmental change, and it causes the emotion and action. Moreover, it is being clarified that the fluctuation of such psychoneuro system influences the function of the immune system $[28,29]$. We have considered the possibility that the hot spring hydrotherapy could affect the hormonal change in blood. As a results of examining 7 kinds of hormonal level in blood, adrenalin level decreased and dopamine level increased, respectively. From the result, there seems to be the close relation for fluctuation of these neuro-modulators level and the adjustment of white blood cells. This linkage is regarded as being in the information on the bidirectional communication between the immune and neuro-endocrine systems. Namely, it was expected that motion and stress modified the immune function through hypothalamus, pituitary and adrenal cortex systems. By pleasant feeling which the hydrotherapy brings about, it seems to generate the change of the internal level of hormones such as adrenalin and acetylcholine related to emotion of the brain and neuroendocrine system. Actually, the adrenalin level lowered in most participants ( 25 persons) at 24 hours later of the hydrotherapy. It was adjusted so that lowering width may correlate with the blood level in previous day. Though the change of the nor-adrenaline was not remarkable, dopamine level was enhanced in all the members. Like this, it was suggested that the balance of the hormones with close relation to the feeling is concerned in the adjustment of leukocyte subset within a short term.

We hope that our work will attract further investigation into the mechanism of how hot spring hydrotherapy benefits the health. In further research, we plan to focus on the mutual interaction between the immune system function and the efficacious period of hydrotherapy, the influence of the hot spring's components and temperature, the physical effect of the spring water, as well as the effect on the individual's mental condition.

\section{CONCLUSIONS}

1) HSH increased total leukocyte count in older ager.

2) $\mathrm{HSH}$ decreased total leukocyte count in younger ager.

3) Granulocyte regulated by HSH in G-rich type.

4) Lymphocyte regulated by $\mathrm{HSH}$ in L-rich type.

5) $\mathrm{HSH}$ regulated $\mathrm{CD} 4, \mathrm{CD} 8, \mathrm{CD} 16$ and $\mathrm{CD} 56 / \mathrm{NK}$ cells in constitution dependent manner.
6) HSH regulated IL-4 producing cell, IFN- $\gamma$ producing cell but less in IL-1.

7) HSH down-regulated serum adrenalin level.

8) HSH up-regulated serum dopamine level.

\section{REFERENCES}

[1] Siiteri, P.K., Febres. F, Clemens, L.E., Chang, R.J., Gondos, B. and Stites, D. (1977) Progesterone and maintenance of pregnancy: Is progesterone nature's immunosuppressant? Annals of the New York Academy of Sciences, 286, 384-397.

[2] Kurashige, S., T. Yoshida, T. and Mitsuhashi, S. (1980) Immune response in sarcoma 10-bearing mice. Annual Report of Gunnma University, 1, 36-44.

[3] Kishida, K., Miyazaku, S., Take, H., Fujimoto, T., Shi, H., Sasaki, K. and Goya, N., (1978) Granial irradiation and lymphocyte subpopulation in acute lymphatic leukemia. Journal of Pediatrics, 92, 785-786. http://dx.doi.org/10.1016/S0022-3476(78)80155-3

[4] Davis, B.K. and Gill, T.J. (1975) Decreased antibody response in the offspring of immunized high responder rats. The Journal of Immunology, 115, 1166-1168.

[5] Shinka, S., Dohi, Y., Komatsu, T., Natarajan, R. and Amano, T. (1974) Immunological unresponsiveness in mice. Immunological unresponsiveness induced in embryonic mice by maternofetal transfer of human globulin. Biken Journal 17, 59-72.

[6] Paul, G., Margaret, S., Liew, Y.F. and Allan, M.M. (1995) CD4+ but Not CD8+ T cells are required for the induction of oral tolerance. International Immunology, 7, 501504. http://dx.doi.org/10.1093/intimm/7.3.501

[7] Auerbac, K. and Clark, S. (1975) Immunological tolerance: Transmission from mother to offspring. Science, 189, 811-813.

[8] Zoeller, M. (1988) Tolerization during pregnancy: Impact on the development of antigen-specific help and suppression. European Journal of Immunology, 18, 1937-1943. http://dx.doi.org/10.1002/eji.1830181211

[9] Auerback, R. and Clark, S. (1975) Immunological tolerance: Transmission from mother to offspring. Science, 189, 811-813. http://dx.doi.org/10.1126/science.1162355

[10] Pence, H., Petty, W.M. and Rocklin, R.E. (1975) Suppression of maternal responsiveness to paternal antigens by maternal plasma. The Journal of Immunology, 114, 525-529.

[11] Aase, J.M., Noren, G.R., Reddy, D.V., Geme Jr. and J.W. (1972) Mumps-virus infection in pregnant women and the immunologic response of their offspring. The New England Journal of Medicine, 286, 379-1382.

[12] Yamaguchi, N., Takahashi, T, Sugita, T., Uchikawa, K., Sakaihara, S., Kanda, T., Ara M. and Kawakita, K. (2007) Acupuncture regulates leukocyte subpopulations in human peripheral blood. eCAM, 4, 447-453.

[13] Shimizu, S., Kitada, H., Yokota, H., Yamakawa, J. and Murayama, T., (2002) Activation of the alternative complement pathway by agaricus blazei murill. Phytomedi- 
cine, 9, 536-545.

[14] Yamaguchi, N., Hashimoto, H., Arai, M, Takada, S., Kawada, N., Taru, A., Li, A.-L., Izumi, H. and Sugiyama, K. (2002) Effect of acupuncture on leukocyte and lymphocyte subpopulation in human peripheral blood-quantitative discussion. The Journal of Japanese Association of Physical Medicine, Balneology and Climatology, 65, 199206.

[15] Yamaguchi, N., Shimizu, S. and Izumi, H., (2004) Hydrotherapy can modulate peripheral leukocytes: An approach to alternative medicine. Complementary and alternative approaches to biomedicine (Edwin L. Cooper, Nobuo Yamaguchi) Kluwer Academic/Plenum Publishers, New York, 239-251.

[16] Wang, X.-X., Katoh, S. and Liu, B.-X. (1998) Effect of physical exercise on leukocyte and lymphocyte subpopulations in human peripheral blood. Cytometry Research, $\mathbf{8}$, 53-61.

[17] Kawakita, K., Shichidou, T., Inoue, E., Nabeta, T. Kitakouji, H., Aizawa, S., Nishida, A., Yamaguchi, N., Takahashi, N., Yano, T. and Tanzawa, S. (2004) Preventive and curative effects of acupuncture on the common cold: A multicentre randomized controlled trial in Japan. Complementary Therapies in Medicine, 12, 181-188.

[18] Yu, F., Takahashi, T., Moriya, J., Kawaura, K., Yamakawa, J., Kusaka, K., Itoh, T., Morimoto, S., Yamaguchi, N. and Kanda, T. (2006) Traditional Chinese medicine and kampo: A Review from the distant past for the future. The Journal of International Medical Research, 34, 231-239.

[19] Abe, S., Yamaguchi, N., Tansho, S. and Yamaguchi, H., (2005) Preventive effects of juzen-taiho-to on infectious disease. Juzen-Taiho-to (Shi-Quan-Da-Bu-Tang) Scientific Evaluation and Clinical Applications: Traditional Herbal Medicines for Modern Times, Edited by Haruki Yamada, Ikuo Saiki.

[20] Abo, T., Kawate, T., Itoh, K. and Kumagai, K. (1981) Studies on the bioperiodicity of the immune response. 1 . Circadian rhythms of human T, B and $\mathrm{K}$ cell traffic in the peripheral blood. Journal of Immunology, 126, 13601363.
[21] Abo, T. and Kumagai, T. (1978) Studies of surface Immunoglobulins on human B lymphocytes. III physiological variations of SIg+ cells in peripheral blood. Clinical Experimental Immunology, 33, 441-452.

[22] Suzuki, S., Toyabe, S., Moroda, T., Tada, T., Tsuka, A., Abo, T., Kawate, T. and Itohl, K. (1981) Studies on the bioperiodicity of the immune response. I. Circadian rhythms of human $\mathrm{T}, \mathrm{B}$, and $\mathrm{K}$ cell traffic in the peripheral blood. The Journal of Immunology, 126, 1360-1363.

[23] Kitada, Y., Okamoto, K., Takei, T., Jia, X, Chen, R, Yamaguchi1, N., Tsubokawa M, Wu, W.-H., Murayama, T. and Kawakita, K. (2013) Hot spring hydro therapy regulate peripheral leukocyte together with emotional hormone and receptor positive lymphocytes according to each constitution/condition. Open Journal of Rheumatology and Autoimmune Diseases, 3, 140-153.

[24] Tonnesen, E., Christensen, N.J. and Brinklov, M.N. (1987) Natural killer cell activity during cortisol and adrenaline infusion in healthy volunteers. European Journal of Clinical Investigation, 17, 497-503. http://dx.doi.org/10.1111/j.1365-2362.1987.tb01148.x

[25] Mandler, R.N., Biddison, W.E. and Mandler, R. (1986) $\beta$-endorphin augments the cytolytic activity and interferon production of natural killer cells. The Journal of Immunology, 136, 934-939.

[26] Simpson, J.R. and Hoffman-Goetz, L. (1990) Exercise stress and murine natural killer cell function. Proceedings of the Society for Experimental Biology and Medicine, 195, 129-135. http://dx.doi.org/10.3181/00379727-195-43131

[27] Moriguchi, S. (1995) Beneficial effects of nutrition and exercise on cellular immune function. Journal of Japan Society of Nutrition and Food Science, 48, 1-8. http://dx.doi.org/10.4327/jsnfs.48.1

[28] Ishigami, T. (1919) The influence of psychic acts on the progress of pulmonary tuberculosis. American Review of Tuberculosis, 2, 4701-4706.

[29] Blalock, J.E. (1989) A molecular basis for bidirectional communication between the immune and neuroendocrine systems. Physiological Reviews, 69, 1-32. 


\section{ABBREVIATIONS}

CAM: Complementary and alternative medicine, trying to promote QOL Combining and/or solely with western medicine.

CD: Cluster of differentiation, showing each name label of lymphocyte with surface characteristics.

CPCA: Cytokine producing cell assay. This method reveals cytokine producing cell number by peering off the surface of lymphocyte, enable to express cell numbers in festival evening, compare than serum cytokine level that correspond to paper tips of post festival.

G-rich type: Granulocyte count over $60 \%$, refer to reference no. 1 .

HSH: Hot spring hydrotherapy by Japanese style at $41 \pm 1 \mathrm{C}$ that free from under wear including foot spa.

L-rich type: Lymphocyte count over $40 \%$, refer to reference no. 1.

MET: Metabolic Rate, 4 Mets $=4$ times high calorie consumption compare to 1 met of resting status

NK cell: Natural killer cell exhibiting CD16 and CD56.

Old ager: Volunteers over 35 years old.

QOL: Quality of life.

Young ager: Volunteers 35 y. o. or less. 